\title{
A Simple and Effective Hardware-in-the-Loop Simulation Platform for Urban Electric Vehicles
}

\author{
B. Tabbache ${ }^{1,2}$, Y. Aboub ${ }^{2}$, K. Marouani ${ }^{2}$, A. Kheloui $^{2}$ and M.E.H. Benbouzid ${ }^{1}$ \\ ${ }^{1}$ University of Brest, EA 4325 LBMS, Brest, France \\ ${ }^{2}$ Electrical Engineering Department, Polytechnic Military Academy, Algiers, Algeria \\ e-mail: Mohamed.Benbouzid@univ-brest.fr
}

\begin{abstract}
This paper deals with hardware-in-the-loop simulation of urban electric vehicles. The proposed platform, which is expected to be used for electric vehicle prototyping, is very simple and effective. Indeed, the induction motorbased powertrain is coupled to DC machine-based load torque emulator taking into account the electric vehicle mechanics and aerodynamics. Experiments are carried-out using the New European Driving Cycle (NEDC) to show that the proposed hardware-in-the-loop simulation system is effective and provides a simple configuration for prototyping electric vehicles.
\end{abstract}

Index Terms -Electrical vehicle, hardware-in-the-loop simulation, induction motor, direct torque control, hysteresis controller, dSPACE DS1102.

\section{INTRODUCTION}

The electric vehicle is one of the solutions recommended by vehicle industries and research organizations to gradually replace conventional vehicles especially in city centers. New powertrain arrangements have been developed in recent years to increase the vehicle performance [1]. Before the application of a new control on a vehicle, validation should be done by simulations of the entire system to check the available torque throughout the operating range. HIL simulation is sometimes used for validation before application to real vehicles.

In recent years, HIL simulation becomes an unavoidable means of experimentation, testing in critical conditions and validation of models and prototypes. This method then provides tests for the control system to prevent costly breakdowns and damaging. Indeed, many groups in the automotive industry have used the HIL simulation for testing electronic control units [2-3].

In this context, this paper proposes a very simple and effective HIL simulation system. Indeed, the induction motor-based powertrain is coupled to a DC machine-based load torque emulator taking into account the electric vehicle mechanics and aerodynamics. The realized HIL simulation platform is composed of two associated electric machine + converter systems: 1) a DC machine fed by a DC-DC converter for the $\mathrm{EV}$ emulation and 2) an induction motor fed by a PWM inverter for propelling the EV.

\section{HIL SIMULATION PLATFORM}

HIL simulation is based on the association of the system hardware (real components) and software (real time simulated/emulated components) parts. Another type of HIL simulation is to test systems using its inputs and outputs

Figure 1 illustrates the different steps of the HIL simulation in the design of electric vehicle prototypes in which there are two platforms:

- The virtual platform that includes EV specification, architecture selection, choice of technologies and components.

- The experimental platform that includes power management, monitoring and control, test bench etc.

The realized HIL simulation platform is depicted by Fig. 2.
VIRTUAL PLATFORM

Global system

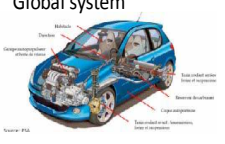

Architecture choice

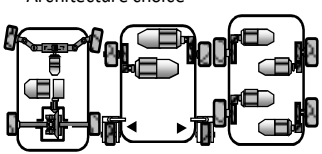

choice of technologies and components

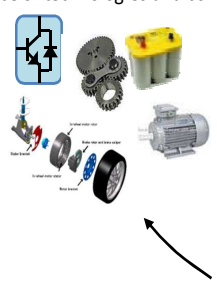

EXPERIMENTAL PLATFORM

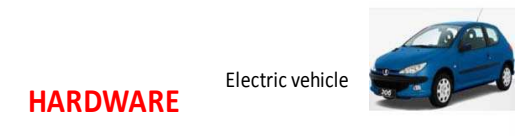

IN

THE

LOOP

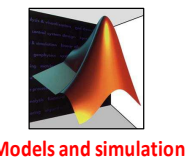

EMC Test

Tested bencl bench of electric vehicle

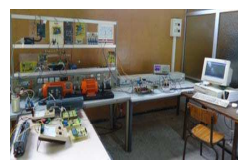

Energy management and control

Fig. 1. HIL simulation typical architecture. 


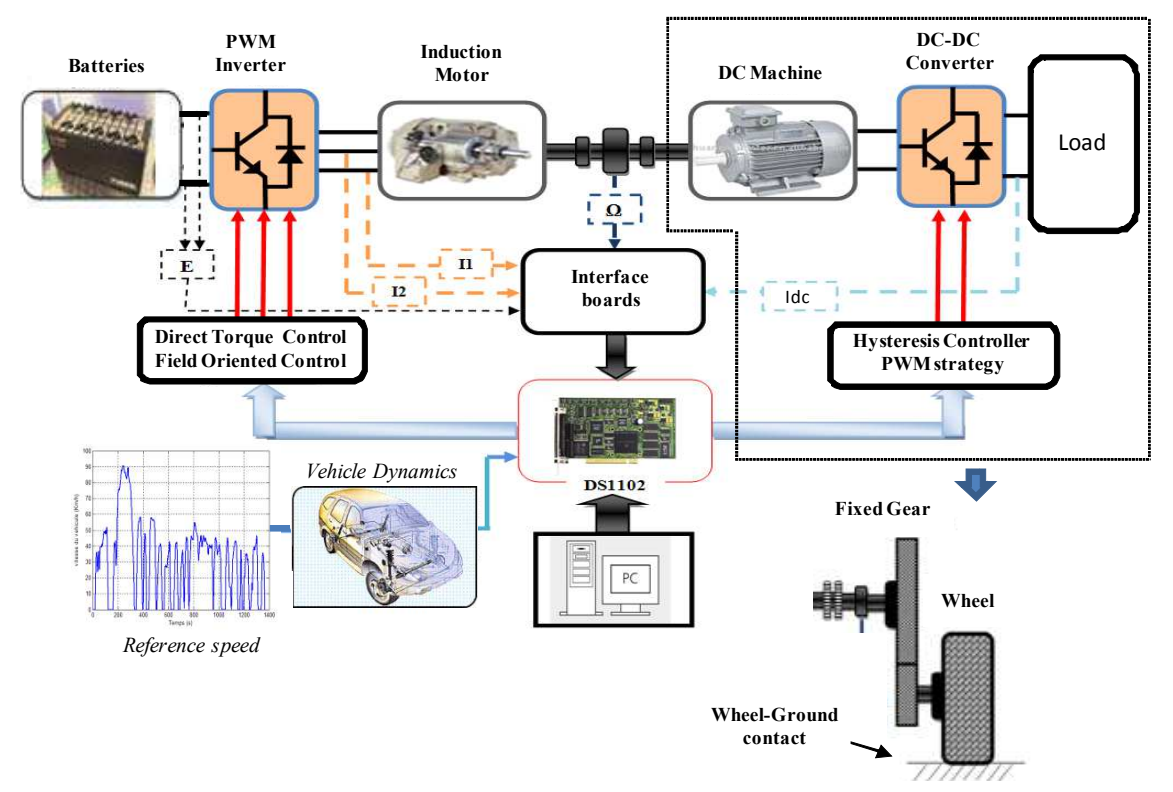

Fig. 2. EV HIL simulation platform.

\subsection{Electric Propulsion System}

The electric propulsion system is composed of an induction motor fed by a PWM inverter. In this presented study, only the DTC is adopted for the induction motor control [4].

The basic idea of the DTC method is to calculate flux and torque instantaneous values only from the stator variables. The input of the motor controller is the reference speed, which is directly applied by the driver on the EV pedal. The control is carried out by hysteresis comparators and a switching logic table selecting the appropriate voltage inverter switching configurations. Figure 3 gives the global configuration of the DTC scheme and also shows how the EV dynamics will be taken into account.

\subsection{EV Load Torque Emulator}

2.2.1. EV dynamics The EV modeling is based on mechanics and aerodynamics principles that allow the evaluation of necessary driving power (Fig. 4) [5].

The road load is then given by

$$
F_{w}=F_{r o}+F_{s f}+F_{a d}+F_{c r}
$$

The power required to drive the EV at a speed $v$ has to compensate the road load $F_{w}$.

$$
P_{v}=v F_{w}
$$

The mechanical equation (in the motor referential) used to describe each wheel drive is expressed by

$$
J \frac{d \omega_{m}}{d t}+T_{B}+T_{L}=T_{m}
$$

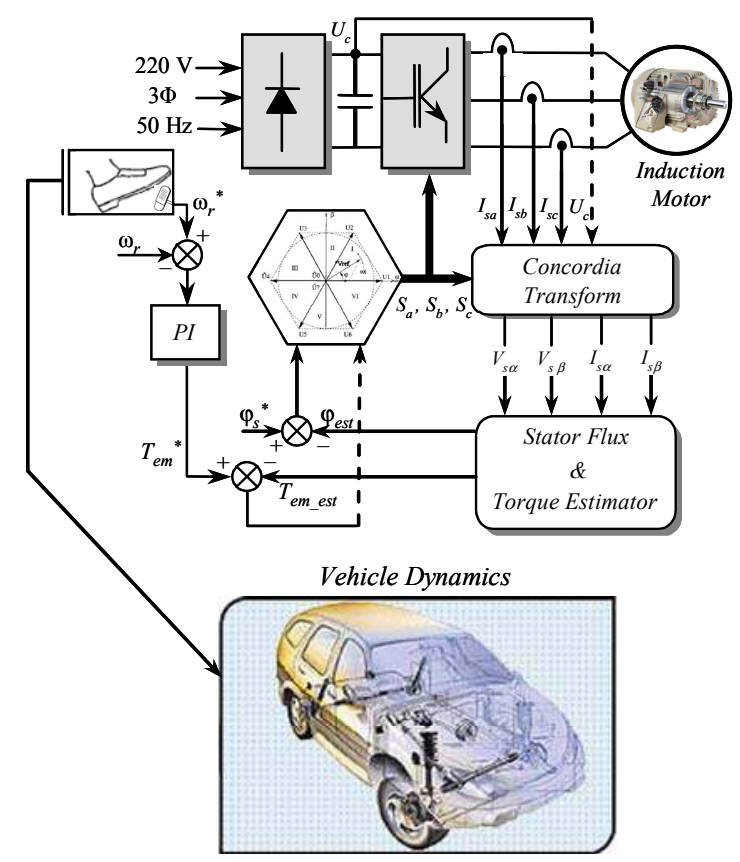

Fig. 3. DTC general configuration.

The following equation is derived due to the use of a reduction gear.

$$
\left\{\begin{array}{l}
\omega_{\text {Wheel }}=\frac{\omega_{m}}{i} \\
T_{\text {Wheel }}=T_{m} i \eta_{t}
\end{array}\right.
$$

The load torque in the motor referential is then given by

$$
T_{L}=\frac{T_{L \text { Wheel }}}{i}=\frac{R}{i} F_{\omega}
$$




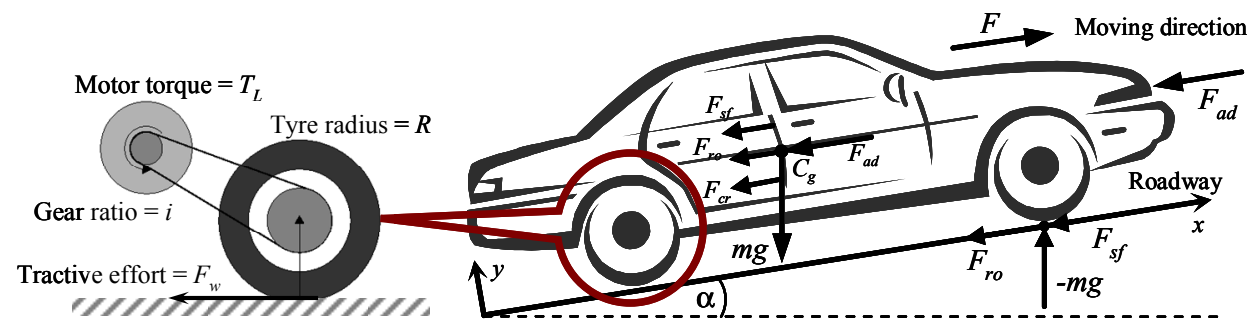

Fig. 4. Elementary forces acting on a vehicle.

2.2.2. EV load torque emulator. The EV load torque emulator is based on DC machine fed by a 4-quadrant chopper to control the generated current. Figure 5 shows then the proposed architecture emulating the EV dynamics.

2.2.3. Emulator Controller Strategy. In this case, the objective is to control the DC machine current in order to track the reference generated by the EV dynamics. The emulator performance, in particular the DC machine current ripples, is related to the reference current generated by the EV dynamics, but also depends on the chopper adopted control strategy. In the proposed HIL platform, two control strategies are investigated: 1) a PWM control (Fig. 6) and 1) a hysteresis control (Fig.7).

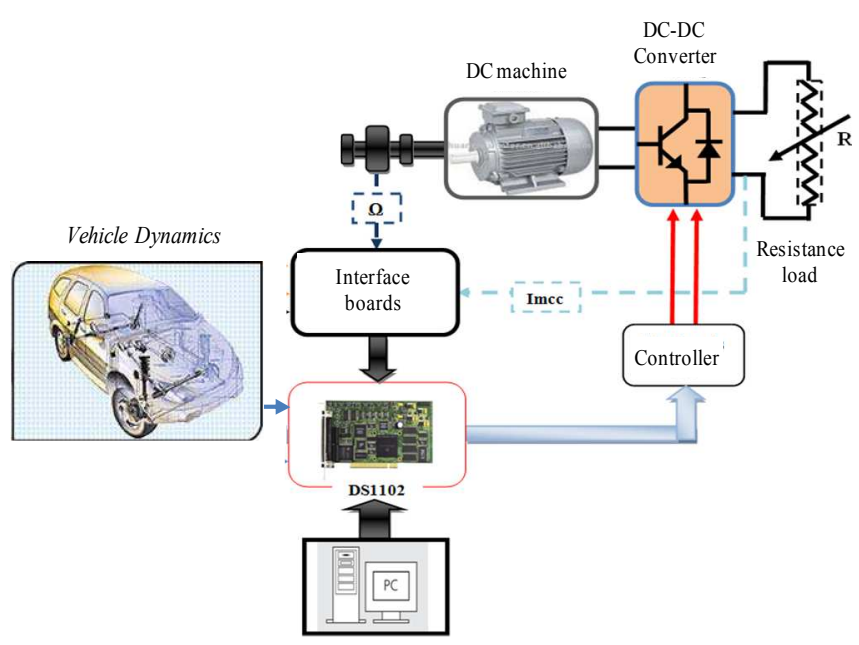

Fig. 5. EV load torque emulator structure.

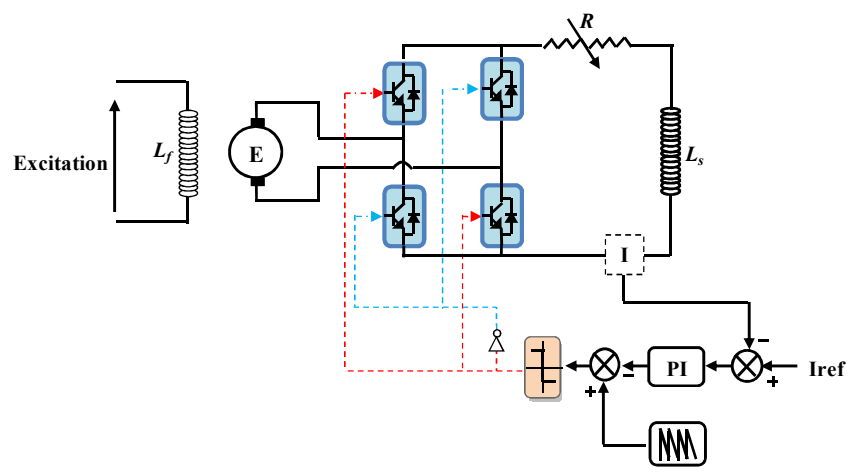

Fig. 6. Chopper PWM control principle.

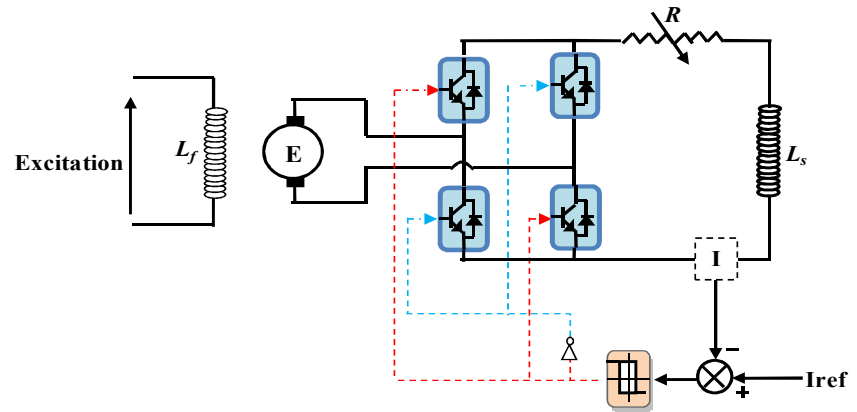

Fig. 7. Chopper hysteresis control principle.

\section{HIL PLATFORM EXPERIMENTAL RESULTS}

\subsection{Test Bench}

The test bench used to validate the proposed HIL simulation platform is illustrated by Fig. 7. It main components, in addition to the induction motor and the DC machine are: 1) a dSPACE - DS1102 development board interfaced to a standard PC, 2) an optical encoder attached to the motor shaft, 3) Hall effect sensors for voltage and current measurements, 4) a PWM inverter, and 5) a DC-DC converter.

\subsection{Experimental Results}

The proposed HIL simulation has been tested using the New European Driving Cycle (NEDC) to assess its effectiveness (Fig. 8) [6].

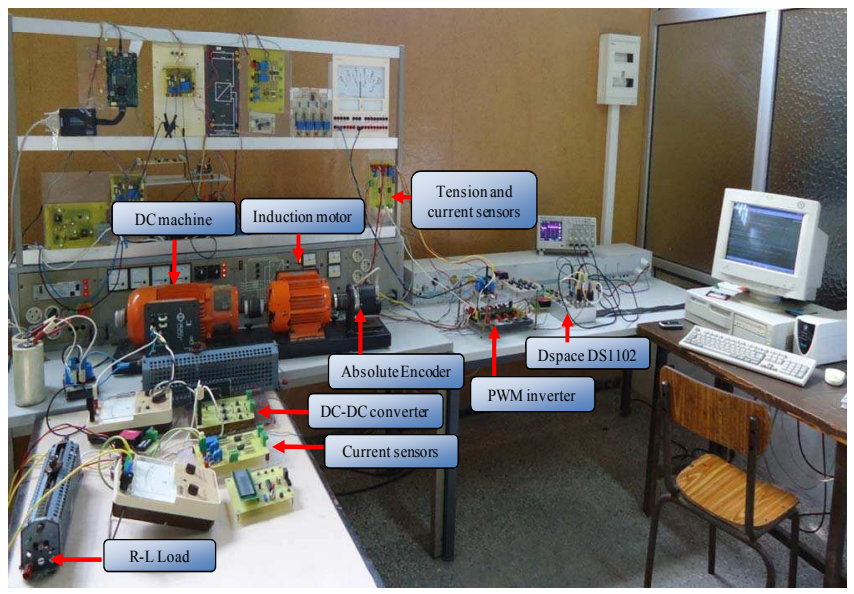

Fig. 7. The experimental setup. 


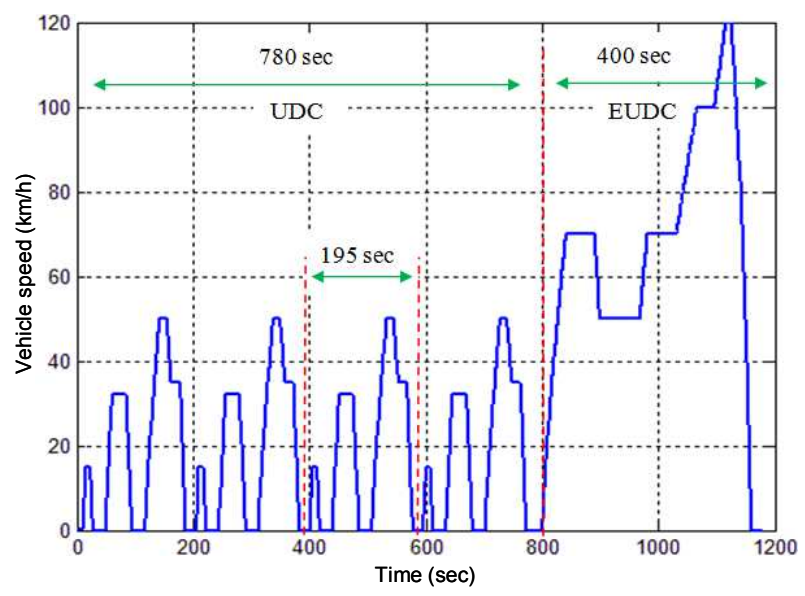

Fig. 8. The NDEC driving cycle.

The objective is here to choose the appropriate control strategy leading to the simplest and best EV emulation.

Figure 9 illustrates experimental results using PWM control of the DC machine. In this case, the induction motor and the DC machine tracking performances are shown by Fig. 9a and Fig. 9b, in terms of speed and current, respectively.

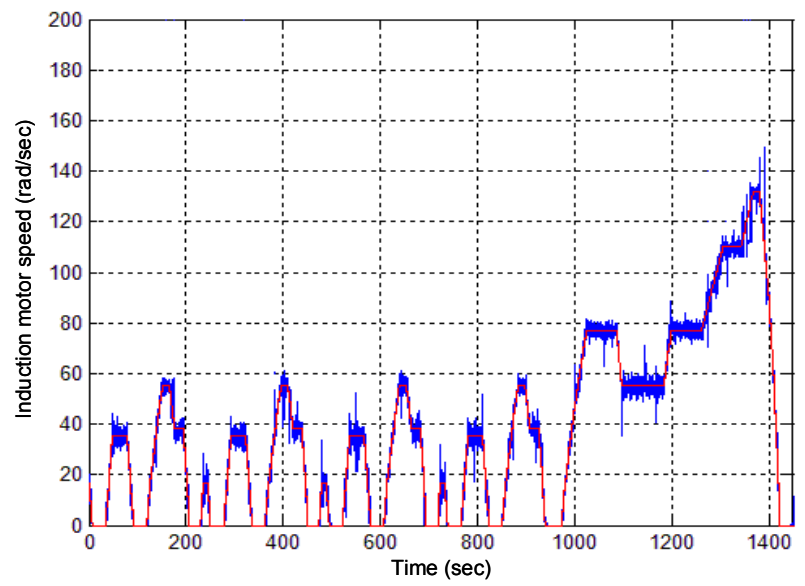

(a) The induction motor speed and its reference.

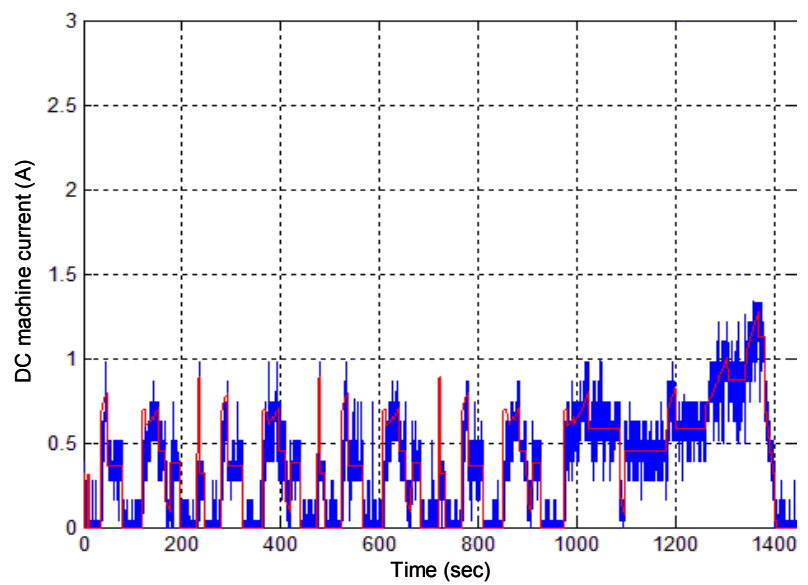

(b) The DC machine current and its reference.

Fig. 10. HIL simulation system response with NEDC driving cycle using PWM control.
The emulation performances using hysteresis control of the DC machine are shown by Fig. 10.

It is obvious that using hysteresis control, less ripples are achieved in terms of current and therefore in terms of speed. Indeed, the PWM technique performances depend on the PI controller parameters that are unfortunately based on those of the DC machine. This is not the case of the hysteresis control technique.

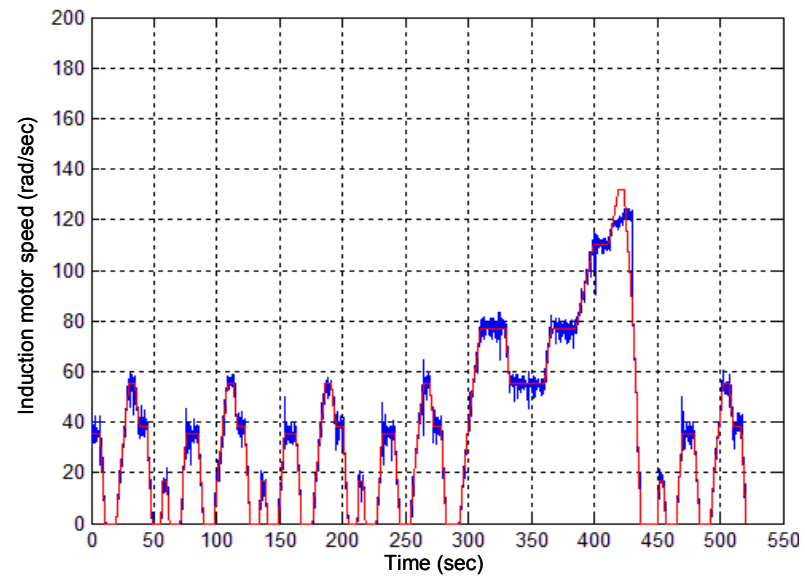

(a) The induction motor speed and its reference.

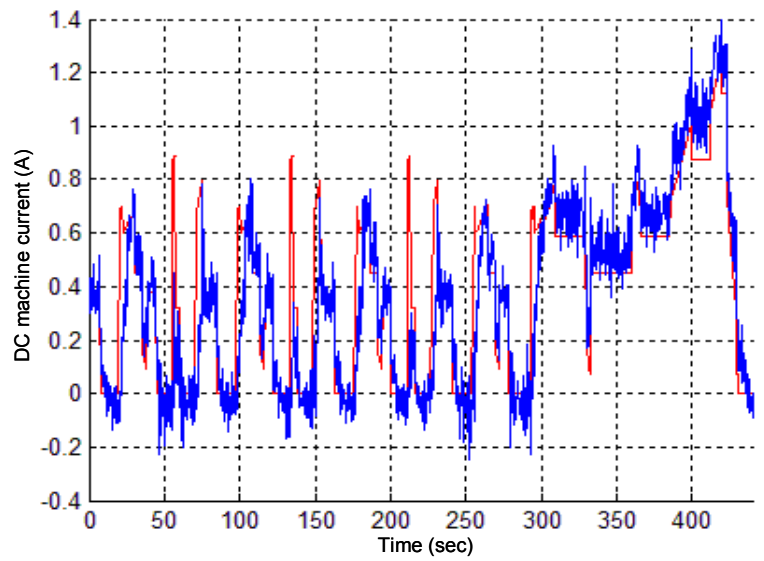

(b) The DC machine current and its reference.

Fig. 10. HIL simulation system response with NEDC driving cycle using hysteresis control.

\section{CONCLUSION}

This paper has proposed a very simple and effective HIL simulation platform devoted to urban electric vehicles. Indeed, the platform uses an induction motor-based powertrain coupled to a DC machine-based load torque emulator taking into account the electric vehicle mechanics and aerodynamics.

Experimental results, in terms of current and speed tracking performances using a NDEC driving cycle, have shown that the proposed HIL platform is effective and provides a simple configuration for prototyping electric vehicles. In this context, the realized platform is currently used with other driving cycles to test other control techniques of the powertrain. 


\section{NOMENCLATURE}

$\mathrm{EV}=$ Electric vehicle;

HIL = Hardware-In-the-Loop;

DTC $=$ Direct Torque Control;

$\mathrm{NEDC}=$ New European Driving Cycle;

$s,(r)=$ Stator (rotor) index;

$\alpha, \beta=$ Synchronous reference frame index;

est = Estimated quantity;

$* \quad=$ Reference quantity;

$V(I)=$ Voltage (Current);

$\varphi \quad=$ Flux;

$\omega_{r} \quad=$ Rotor electric speed;

$T_{e m}=$ Motor torque;

$v \quad=$ Vehicle speed;

$F_{w} \quad=$ Road load;

$F_{r o}=$ Rolling resistance force;

$F_{s f}=$ Stokes or viscous friction force;

$F_{a d}=$ Aerodynamic drag force;

$F_{c r}=$ Climbing and downgrade resistance force;

$P_{v}=$ Vehicle driving power;

$J \quad=$ Total inertia (rotor and load);

$\omega_{m} \quad=$ Electric motor mechanical speed;

$T_{B} \quad=$ Load torque accounting for friction and windage;

$T_{L} \quad=$ Load torque;

$T_{m} \quad=$ Electric motor torque;

$i=$ Transmission ratio;

$\eta_{t}=$ Transmission efficiency;

$R \quad=$ Wheel radius;

\section{REFERENCES}

[1] C.C. Chan, A. Bouscayrol and K. Chen, "Electric, hybrid, and fuelcell vehicles: Architectures and modeling," IEEE Trans. Vehicular Technology, vol. 59, n², pp. 589-598, February 2010.

[2] L. Gauchia and J. Sanz, "A per-unit hardware-in-the-loop simulation of a fuel cell/battery hybrid energy system," IEEE Trans. Industrial Electronics, vol. 57, n4, pp. 1186-1194, April 2010.

[3] R. Trigui, B. Jeanneret, B. Malaquin and C. Plasse, "Performance comparison of three storage systems for mild HEVs using PHIL simulation," IEEE Trans. vehicular technology, vol. 58, n⿳8, pp. 3959-3969, October 2009.

[4] B. Tabbache, A. Kheloui and M.E.H. Benbouzid, "An adaptive electric differential for electric vehicles motion stabilization," IEEE Trans. Vehicular Technology, vol. 60, ${ }^{\circ} 1$, pp. 104-110, January 2011.

[5] B. Tabbache, A. Kheloui and M.E.H. Benbouzid, "Design and control of the induction motor propulsion of an electric vehicle," in Proceedings of the 2010 IEEE VPPC, Lille (France), pp. 1-6, September 2010.

[6] A. Froberg and L. Nielsen, "Efficient drive cycle simulation," IEEE Trans. Vehicular Technology, vol. 57, n³, pp. 1442-1453, May 2008. 